Marquette University

e-Publications@Marquette

College of Nursing Faculty Research and

Publications

Nursing, College of

$5-1-2008$

Refinement of the Shared Care InstrumentRevised: A Measure of a Family Care Interaction

Margaret Sebern

Marquette University, margaret.sebern@marquette.edu

Accepted version. Journal of Nursing Measurement, Vol. 16, No. 1 (2008): 43-60. DOI. (C) 2008 Springer Publishing Company. Used with permission. 


\section{Refinement of the Shared Care Instrument-Revised: A Measure of a Family Care Interaction}

By Margaret D. Sebern

This study's purpose was to evaluate the psychometric properties of the Shared Care Instrument-Revised (SCl-R) in a sample of family care dyads. The SCl-R was developed to measure the construct of shared care, which is a system of three constructs (communication, decision making, reciprocity) used in family care to exchange support. An important aspect of evaluating the SCI-R was to create a measure that is statistically sound and meaningful for patient and caregivers. Surveys were mailed to randomly selected home health dyads, which included 223 patients and 220 caregivers. Reliability and confirmatory factor analysis, and concurrent validity were examined. Internal consistency reliability of the patient subscales ranged from 0.74 to 0.76 , and from 0.72 to 0.78 for caregiver sub-scales. Factor analysis supported the underlying theoretical basis of the SCI-R. Construct validity also was supported using the hypothesis-testing approach. One major challenge in family care research is to develop methods and tools to study the dynamic characteristics of close relationships. The findings from this study support further use of SCI-R to study how shared care facilitates the exchange of support and the influence shared care has on outcomes for both patients and caregivers.

A tremendous amount of health care is provided by family and friends (Donelan et al., 2002). Family care refers to unpaid assistance to a patient by family and friends in their place of residence (Archbold et al., 2001). Family care involves complex interactions that can impact the quality of the dyadic relationship and health outcomes for both patients and caregivers (Beach et al., 2005; Liang, Krause, \& Bennett, 2001; Lyons, Zarit, Sayer, \& Whitlatch, 2002). Patients and family cannot provide care alone, and they need guidance, support, and skills to manage often complex care. Family care is an important clinical issue because of the effects of social relationships on health, and family involvement in care is necessary to achieve optimal outcomes from nursing interventions (Grady et al., 2000).

Family care by its nature involves at least two people in a close relationship. Reis and Collins (2000) suggested that close relationships are the context for the provision and receipt of social support. Yet not all close relationships are supportive. Reis and Collins (2000) suggested that more research efforts are needed to understand the relationship processes that foster or inhibit the expression and reception of support. Cohen, Gottlieb, and Underwood (2000) cited a 
need for more careful measurement of the functions and sources of perceived and received support.

This study begins to address this gap in our understanding of how relationships foster and inhibit the expression of social support, in that it evaluated an instrument developed to measure a supportive family care interaction called shared care. In previous work, shared care was identified as a construct of interest in a theoretical model of family care interactions. Shared care was defined as an interpersonal process used by home care patients and family caregivers to exchange support and manage a chronic illness (Sebern, 1996, 2005b). Although there are many components of family care interactions, the three components of shared care identified in the naturalistic inquiry were communication, decision making, and reciprocity (see Figure 1). Shared care interactions require cognitive ability to communicate, make decisions, and engage in reciprocal actions. The Shared Care Instrument-Revised (SCI-R) was developed and tested to measure the construct (Sebern, 2005a).

\section{Purpose of the Study}

This study was designed to evaluate the psychometric properties of the SCI-R in a new sample of home health family care dyads. An important aspect of the SCl-R's development was to create a measure that was statistically sound and meaningful for both patients and caregivers, which could be used to assess shared care interactions. To achieve this purpose the authors used factor analysis to examine a three-factor structure and evaluated the reliability and construct validity of scores. A three-factor solution was based on the conceptualization of shared care as a system of three constructs (communication, decision making, reciprocity). The author chose not to look at the global construct of shared care because shared care is a system of constructs and the global construct would disguise the unique functions of the components. Four hypotheses were tested to evaluate the construct validity of SCI-R.

For both the patient and caregiver,

1. shared care is a three-factor structure,

2. shared care components will correlate in a positive direction with positive dyadic interactions,

3. shared care components will have an inverse correlation with dyadic strain, and

4. shared care components will have an inverse correlation with depressive symptoms.

\section{Background and Conceptual Framework}

Shared care is a dyadic process. Dyadic processes are based on the premise that each 
participant affects and is affected by the other (Gayle \& Preiss, 2002 ). Shared care is assumed to occur in a close relationship. There is a logical link between shared care and social support because shared care is conceptualized as a system of constructs (communication, decision making, and reciprocity) used to exchange support.

Researchers posed that supportive family and friends have the capacity to alter the relationship between a person's need for assistance in chronic illness and dyadic strain (Bass, McKee, Deimling, \& Mukherjec, 1994). Bass and colleagues defined dyadic strain as deterioration in the quality of a patient's and caregiver's relationship as a result of care-giving. Supportive relationships may alter the negative effects of chronic illness on dyadic strain by reducing the consequences of the patient's impairment. For example, when a chronically ill patient is able to exchange gratitude and appreciation (if not other tangible rewards) in return for assistance from a caregiver, these rewards may make the relationship more equitable, mutually satisfying, and less stressful (Bass, Tausig, \& Noelker, 1989). Bass and colleagues developed the original tool used in this study to evaluate the influence of shared care on the dyadic relationship.

Researchers studied components of shared care separately and found family communication (Pruchno, Burant, \& Peters, 1997), decision-making satisfaction (Deimling, Smerglia, \& Schaefer, 2001), and reciprocity (Beach, Schulz, Yee, \& Jackson, 2000) influenced variables such as relationship quality, mood, depressive symptoms, and wellbeing. Shared care's theoretical and operational definitions are based on field studies and a review of the literature (Sebern, 2005b). Shared care was defined as a family care interaction with three components (communication, decision making, and reciprocity). Shared care communication is conversations between the patient and caregiver about symptoms, feelings, and providing advice to shape the meaning of the situation for the dyad. Patients may underreport their experience to a caregiver, and caregivers may be uncertain about patient difficulties because they have inadequate information about the illness experience. Negative statements were used to measure communication (e.g., I have no one to talk to about how I am feeling). Several other researchers identified how communication and interpersonal agreement influenced caregiver burden and depressive symptoms. For example, Pruchno and colleagues (1997) found that high agreement among multigenerational caregivers about patient problem behaviors contributed to better mental health outcomes for caregivers. Lyons, Zarit, Sayer, and Whitlatch (2002) found that discrepancy about problem behaviors among family care dyads contributed to dyadic relationship strain and poor mental health outcomes (Lyons et al., 2002).

Shared care communication leads to decision making. Shared care decision making was

\section{Sebern 3}


defined as a patient's capacity to seek information and be involved in decisions about his or her care. An example of a decision-making item was, When I am not feeling well, I decide when to call the doctor. Riegel and colleagues (2004) identified decision making as a major component of self-care in heart failure. Other researchers studied the influence of decision making on caregiver outcomes. For example, Deimling and colleagues (2001) examined the effects of satisfaction with decision making on caregiver's depressive symptoms. These researchers found that family adaptability, caregiver type, and decision-making satisfaction predicted depressive symptoms.

Shared care reciprocity was characterized by empathy, listening, and partnership when providing and receiving assistance. An example of a reciprocity item was, We have a partnership. Other researchers corroborate that psychological well-being was enhanced when caregivers provided assistance and managed potential strain and burden (Kramer, 1997). Beach and colleagues (2000) found that help provided by a caregiver to a patient can result in decreased caregiver anxiety and depressive symptoms. Several researchers suggested that patients not only receive support from but also provide substantial support to their caregiver, and these acts of reciprocity are important to well-being (Bass et al., 1989; Liang et al., 2001).

\section{Procedures for Instrument Development}

The SCl-R was developed and tested to measure the construct of shared care. In a prior exploratory factor analysis, the original three components of shared care were supported, and a fourth component, balance, was identified (Sebern, 2005a). The balance items consisted of negatively worded items originally conceptualized as low levels of shared care communication (e.g., We always disagree about the cause of our health problem) and reciprocity (e.g., I get no rewards for the caring I do). A decision was made to delete the balance items from the SCI-R because the balance factor did not support the three postulated components of shared care.

In the previous exploratory factor analysis, correlations between shared care and a reliable and valid measure of relationship quality (mutuality) supported the construct validity of the SCI. Mutuality is a construct defined as an enduring quality in a relationship consisting of love, shared pleasurable activities, shared values, and reciprocity (Archbold, Stewart, Greenlick, \& Harvath, 1992). Mutuality and shared care are similar in that reciprocity was conceptualized as an important component of family care interactions; however, the other components are related but different. Significant correlations between the mutuality and shared care components supported the construct validity of the SCI. Based on the findings of the exploratory factor analysis, the instrument was revised and called the Shared Care Instrument-Revised (SCI-R).

\section{Sebern 4}




\section{Administration, Description, and Scoring of SCI-R}

The initial version of the SCI-R had a total of 24 items. However, the final version of the SCl-R consisted of 19 items; 5 communication, 6 decision making, and 8 reciprocity items. The $\mathrm{SCl}-\mathrm{R}$ asked participants to rate their agreement with items on a four-point Likert-type scale ranging from (1) strongly disagree to (4) strongly agree. Five communication items were negatively worded and were reverse coded. After reverse coding negatively worded items, subscale scores are obtained by adding the ratings of the relevant items. Higher scores reflected better communication, decision making, and reciprocity for each member of the dyad. The SCI-R has a patient version and a caregiver version. The communication and reciprocity items are the same in both versions. However, to measure caregiver views of patient decision-making capacity, the caregiver SCI-R asked caregivers to report their perceptions of the patient's decision-making capacity (e.g., When my family member is not feeling well, s/he decides when to call the doctor).

\section{Methods}

\section{Sample}

A home health care agency serving both urban and rural populations in a Midwestern state provided access to patients and caregivers for this study. Personnel from the agency's information system department selected patients from their databases who met study criteria. Criteria for inclusion were the following: over 18 years of age, cognitive ability and vision intact, and living with a person who provided unpaid assistance. The agency personnel identified 1,107 eligible cases. From the list of eligible patients, 579 cases were randomly selected, using a table of random numbers, and were invited to participate in the study. A total of 223 patients and 220 caregivers returned completed surveys, and this data were used to examine the reliability and factor structure of the SCl-R. For descriptive purposes, a subset of 198 matched dyads was used to examine the similarity of scale scores within patient and caregiver dyads, and for significant differences in patient and caregiver scores.

\section{Procedures}

Institutional review board approval was obtained from university and health care organizations. Survey packages were mailed to 579 home health care family dyads. Each survey package included a patient and a caregiver version of the SCI-R, Center for Epidemiologic Studies Depression Scale (CES-D), Dyadic Relationship Scale (DRS), demographic questions, a measure of functional status, written instructions, and a self-addressed stamped return envelope. 
Both members of a dyad were encouraged to participate. Since all participating patients had a person providing them with assistance, if only one member of the dyad decided to participate, their survey was included in data analysis. Participants were asked not to talk to the other member of the dyad about their answers until they had completed the survey. Patient data and caregiver data were analyzed separately, except for within dyad analysis of means and similarity of scale scores.

To support dyad participation, a prenotification letter was mailed prior to mailing the survey package, a $\$ 2.00$ token of appreciation was clipped to each survey, and a postcard reminder was sent one week after the survey. At 4 weeks, a second survey was sent to non-responders, and at 6 weeks nonresponders received a follow-up phone call to inquire about the survey. In a few cases participants provided a reason for not participating. Common reasons were language differences (e.g., patient spoke Russian or Spanish), patient hospitalized, too busy, and wrong contact information. About $4 \%$ of patients $(n=18)$ did not participate because of death prior to receiving the survey.

\section{Instruments}

The primary construct of interest in this study was shared care. However, to evaluate construct validity of the SCI-R, the DRS (Poulshock \& Deimling, 1984) and CES-D (Radloff \& Teri, 1986) were administered.

\section{The Dyadic Relationship Scale (DRS).}

The DRS has been revised since it was first presented by Poulshock and Deimling (1984). The original 11-item scale, which was based on previous measures of caregiver stress and burden (Zarit, Reever, \& Bach-Peterson, 1980), assessed the caregiver's perspective of relationship strain associated with providing care to older family members. More recently, items have been added that assess the positive aspects of providing care and the patient's perception of the dyad's relationship, while items have been deleted that reflect the broader family relationships (Bass, Clark, Looman, McCarthy, \& Eckert, 2003; Clark, Whitlatch, \& Tucke, 2005; Feinberg, Whitlatch, \& Tucke, 2000; Menne, 2006). DRS items assess a variety of potential relationship stressors, including Because of my health condition, I felt resentful towards my family member (patient version) and, Because of helping my family member, I felt resentful towards my family member (caregiver version). An example of an item measuring patient relationship quality is, Because of my health condition, I have learned good things about myself. For this study we administered both patient and caregiver versions, which included a four-option response $(1=$ strongly disagree, $2=$ disagree, $3=$ agree, $4=$ strongly agree $)$. The patient version

\section{Sebern 6}


(10 items) and the caregiver version (11 items) have two subscales: dyadic strain and positive dyadic interaction. Higher scores on each of these scales indicated higher levels of strain and positive interaction, respectively. Sebern and Whitlatch (2007) reported a two-factor DRS solution which included dyadic strain and positive dyadic interaction. Internal consistency was acceptable for dyadic strain (patient alpha $=0.84$; caregiver alpha $=0.89$ ) and positive dyadic interaction (patient alpha $=0.86$; caregiver alpha $=0.85$ ).

Center for Epidemiologic Studies Depression Scale (CES-D; Radloff \& Teri, 1986).

Depressive symptoms were measured using the CES-D, a 20-item, four-response option scale, with a coefficient alpha of 0.85 (Radloff \& Teri, 1986). Higher scores on the CES-D indicate higher levels of depressive symptoms, and a cut-score of 16 or higher is commonly used to indicate the presence of depressive symptoms (McDowell, 2006). In the current study, the Cronbach's alphas for the CES-D were .89 (patients) and .88 (caregivers).

Patient functional status was defined as a patient or caregiver's subjective perception of the patient's limitation in normal activity. We measured patient functional status for descriptive purposes, with the Karnofsky Index of Performance Status (KPS). The KPS has 11 categories describing a patient's limitation in normal activity (e.g., patient's ability to work, performance of normal activities, and need for assistance). KPS scores range from 1 (he or she is able to carry on with normal activity including work) to 10 (his or her condition is a fatal process progressing rapidly). Higher KPS scores indicated the patient required more assistance from caregivers. KPS construct validity was supported by moderate correlations between the KPS and Katz Activities of Daily Living (ADL) scores (Kendall's tau $=0.44$ ). KPS also had strong correlations with a measure of quality of life (Kendall's tau $=0.68$; Mor, Laliberte, Morris, \& Wiemann, 1984). Mor and colleagues (1984) reported an interrater reliability of 0.97 for the KPS. In the current study the intraclass correlation between the patient and caregiver KPS ratings was 0.75 (95\% confidence interval $=0.68$ to 0.80 ), suggesting that the patient and caregiver perceived the patient's need for assistance similarly.

\section{Approaches to Reliability and Validity Testing}

Because shared care was postulated to be a system of three constructs (communication, decision making, and reciprocity) a confirmatory factor analysis was conducted using principal axis components. A three-factor solution was analyzed using the following criteria: (a) factors had eigenvalues greater than 1, (b) change in slope of scree plot, (c) items loaded on a factor as postulated for patients and caregivers ( $>0.40$ ), and (d) interpretability of factors. Because shared care was conceptualized as a system of three unique constructs, a solution using varimax 
(orthogonal) rotation was selected because with varimax rotation the explained variances among factors are assumed not to overlap (Pett, Lackey, \& Sullivan, 2003).

Once a three-factor structure was identified in the data, internal consistency was evaluated (Cronbach's alpha). Finally, relationships among shared care components and positive dyadic interactions, dyadic strain, and depressive symptoms were examined. The Statistical Package for the Social Sciences (SPSS, 1999) subprograms Frequencies, Factor, Reliability, Paired T Test, and Correlations were used to compute demographic analysis and instrument psychometric properties.

The analysis included evaluating for patterns of missing data. Most missing data were due to skipped pages or randomly omitted answers. Cases were deleted if more than $15 \%$ (i.e., 5 ) of SCI-R scale items were missing. Thirty-seven patient cases and 26 caregiver case were deleted because of missing more than $15 \%$ of data. Using the remaining cases, patterns of missing data were analyzed, and none of SCI-R items were missing more than six data points. Multiple imputation methods impute missing data by imposing a probability model on the complete data (observed and missing values; Schafer, 1997). The final sample size was 223 patients and 220 caregivers, which was a $38 \%$ response rate.

\section{Results}

As can be seen in Table 1, patients were on average 66 years of age, mostly White, and only $44 \%$ female. The most frequent patient medical conditions were circulatory, musculoskeletal, neoplasm, and diseases of the skin. Most patients had completed high school (63\%), and most were spouses/partners of their caregiver. On average the patient and caregiver knew each other for 42 years. When patients were asked if they were a caregiver or a care receiver, $36 \%$ stated they were a care receiver, and $43 \%$ reported they were both a caregiver and care receiver. The patient median score for the KPS was 4, indicating half of patients reported some limitation in normal activities.

Also as seen in Table 1, the average caregiver was 64 years old, mostly White and female (64\%). Most caregivers completed high school (62\%), and $80 \%$ of caregivers were spouses/partners. Forty-five percent of caregivers identified their role as primarily caregiving, and $28 \%$ reported that they were a giver and recipient of care. Therefore, participants who viewed themselves as givers and recipients of care may indicate that they exchange substantial assistance to each other over the duration of their relationship. 


\section{Internal Consistency Reliability}

Reliability of Patient Subscales. Estimates of internal consistency reliability for the three patient subscales scores were adequate. The internal consistency of the subscale scores was not improved substantially by deleting any of the items. Cronbach's alpha for the patient scales were 0.75 (communication), 0.74 (decision making), and 0.76 (reciprocity). Descriptive statistics, including item means, subscale means, and standard deviations, were computed and examined. On a four-point scale, where $1=$ completely disagree to $4=$ completely agree, patient item means ranged from 2.9 (communication and reciprocity) to 3.0 (decision making). Subscale means and standard deviations are reported in Table 2.

Reliability of Caregiver Subscales. Estimates of internal consistency reliability for the three caregiver subscales scores were adequate. The internal consistency of the subscale scores was not improved substantially by deleting any of the items. Cronbach's alphas for the caregiver scales were 0.76 (communication), 0.72 (decision making), and 0.78 (reciprocity). Descriptive statistics, including item means, subscale means, and standard deviations, were computed and examined. Caregiver item means were 2.8 (communication), 2.9 (decision making), and 3.0 (reciprocity). Subscale means and standard deviations are reported in Table 2.

\section{Construct Validity}

Analysis of Patient Three-Factor Structure of the SCI-R. For conceptual and statistical reasons, a confirmatory factor analysis specifying three factors was conducted on 24 shared care items using principal axis component factor analysis using varimax rotation. The patient three-factor extracted solution was analyzed statistically and conceptually. Bartlett's test was significant for the patient group $\left(x^{2}=1493, d f=276, p=.000\right)$. The KMO statistic was 0.75. A Kaiser-Meyer-Olkin (KMO) test statistic of .60 or higher indicates that a correlation matrix is factorable (Pett et al., 2003).

Principal components analyses support a three-factor structure in both groups. The first three components explained the most variance, eigenvalues were greater than 3 , and each of these factors explained at least $8 \%$ of variance. The patient scree plot indicated a change in the slope of the line at three factors, and all but five items loaded on factors as postulated. The three-component structure explained $39 \%$ of the patient total item variance.

On visual inspection, some patient items in the scale appeared weak. The following criteria were used to evaluate weak items: (a) items did not load on the factor as originally conceptualized (factor loading < .40), (b) items loaded on two or more factors (> .30), (c) item-to-total correlations less than 0.30 , and (d) interpretability of factors. Using these criteria the 
author identified five weak items (three reciprocity and two decision-making items) in the patient structures. Two reciprocity $(\mathrm{R})$ items did not load on reciprocity. These two items were, Before he or she tells me I always know there is something wrong (R-15) and, If he or she is uncomfortable, then he or she tells me (R-16). One reciprocity item, We always agree about what is causing our health problems (R-17) loaded 0.33 on reciprocity. Item-to-total correlations for these three items were 0.18 to 0.28 in the patient structure.

Two decision-making items loaded less than 0.23 on the patient decision-making factor. These were, When my family member is sick the best way to handle problems is for me to tell her what I think, and let her make up her mind (DM-28) and, My family member is responsible for his own body when he is sick (DM-29). Item-to-total correlations for these two items were 0.12 to 0.31 in the patient structure. These five items were deleted because of weak factor loadings, low item-to-total correlations, and because the goal was to create a stable factor structure across both groups.

The preliminary patient analysis led to the retention of 19 items whose properties were tested in the final step of the factor analysis. Principal axis component factor analysis of 19 shared care items supported three components with eigenvalues greater than 1 , and explained $47 \%$ of the variance in the patient data. All but 2 of the 19 patient items loaded on the factors as expected. Communication item C-1 ( There is no one to talk with about how I am feeling, reverse coded) loaded 0.32 on Communication, and 0.44 with Reciprocity. And reciprocity item R-26 (When my family member tells me something hurts I check it out) loaded 0.37 with patient Decision Making, and 0.30 with Reciprocity. Finally, communication item C-3 (I never ask for advice about my health problems ) cross-loaded with the communication factor (0.50), and with the reciprocity factor (0.45; see Table 3$)$. For purposes of interpretability of factors and comparison of factor structure across groups, all 19 items were retained on patient factors as originally conceptualized.

Examination of the item-to-total correlations indicated that all patient items positively correlated with their respective subscale total score. Overall, patient subscale item-to-total correlations ranged from 0.34 to 0.66 . This range of item-to-total correlations was considered to be acceptable because all items had positive correlations above the cutoff of .30 (Nunnally \& Bernstein, 1994; see Table 2). Patient factors were correlated with other patient factors. Low to moderate correlations were found between patient factors, such as Decision Making and Communication ( $r=-0.04)$ and Decision Making and Reciprocity $(r=0.41$; see Table 4).

Analysis of a Caregiver Three-Factor Structure of the SCI-R. Twenty-four caregiver shared care items were entered into principal axis component factor analysis, and three factors 
were specified. The three-factor extracted solution was analyzed statistically and conceptually. Bartlett's test was significant for caregiver group $\left(x^{2}=1548, \mathrm{df}=276, p=.001\right)$. The KMO statistic was 0.77 . Component analysis indicated the first three components explained the most variance; eigenvalues were greater than 3 , and each of these factors explained at least $9 \%$ of variance. The caregiver scree plot indicated a change in the slope of the line at three factors, and all but five items loaded on factors as postulated. The three-component structure explained $40 \%$ of the caregiver total item variance.

On visual inspection, similar items that did not load with patient factors were weak on the caregiver scale (three reciprocity and two decision-making items). The three reciprocity items had factor loadings less than .40 on reciprocity. These three items were, Before he or she tells me I always know there is something wrong (R-15), If he or she is uncomfortable, then he or she tells me (R-16), and, We always agree about what is causing our health problems (R-17). Item-to-total correlations for these three items were 0.29 to 0.37 for the caregiver reciprocity scale.

Two decision-making items loaded less than .25 on the caregiver decision-making factor. These were, When my family member is sick the best way to handle problems is for me to tell her what I think, and let her make up her mind (DM-28) and My family member is responsible for his own body when he is sick (DM-29). Item-to-total correlations for these two items were 0.13 to 0.17 in the caregiver structure. Since the goal for instrument development was to identify a stable structure across patient and caregiver groups, these five items were deleted from the caregiver scale. This analysis led to the retention of the identical 19 items used in the final step of the patient factor analysis.

Principal axis component factor analysis of 19 shared care items supported three factors and explained $46 \%$ of the variance in the caregiver data (see Table 3). Further support of the construct validity of the caregiver SCI-R was evident in the item-to-total correlation. Overall, caregiver subscale item-to-total correlations ranged from 0.35 to 0.68 , except for one item. DM-31 had an item-to-total correlation of 0.29 , and the factor loading for DM-31 was 0.42 . Because of the marginal item-to-total correlation and the adequate factor loading for DM-31, this item was retained on the DM scale. Caregiver factors were correlated with other caregiver factors and presented in Table 4. Correlations were moderate between caregiver factors, such as Decision Making and Communication $(r=0.38)$ and Reciprocity and Communication $(r=0.40$; see Table 4).

There were no differences between patient and caregiver mean scale scores except for reciprocity and CES-D scores. Significant differences were identified between patient and 
caregiver reciprocity and between patient and caregiver CES-D scores. These findings suggest that patients had less shared care reciprocity and more depressive symptoms than caregivers. These findings also support the SCl-R's ability to discriminate levels of shared care between groups. See Table 5 for subscale means, standard deviations, and $t$ values.

For descriptive purposes, correlation coefficients were used to measure the similarity of the dyad members for the scale scores. Cohen (1992) defined 0.50 as a large correlation, 0.30 as moderate, and 0.10 as small. Kenny, Kashy, and Cook (2006) suggest that the degree of similarity in dyadic data depends on the type of dyad studied and the type of variable measured. Table 6 reports correlations within the dyads scale scores, which were small $(0.23)$ to moderate (.46).

Names for the Factors. Names for the factors in this factor analysis were derived from the construct of shared care (Sebern, 2005b). The communication factor implied that a patient and caregiver talked with each other about symptoms and asked for advice. The decision-making factor denoted a patient's capacity for making decisions about care. The reciprocity factor indicated empathy, listening, and partnership in managing the illness.

Assessment of Construct Validity Using Hypothesis Testing With Patient Data. In the final aspect of the analysis, the construct validity hypotheses were evaluated. For the patient subscales, hypothesis 2 and 3 were supported. As seen in Table 7, patient communication correlated moderately and inversely with dyadic strain. Patient decision making moderately correlated with positive dyadic interactions and inversely with dyadic strain. Patient reciprocity correlated moderately with positive dyadic interactions and inversely with dyadic strain. Hypothesis 4 was partially supported in that there was an inverse correlation only between patient communication and patient CES-D scores (see Table 7).

\section{Assessment of Construct Validity Using Hypothesis Testing With Caregiver Data.}

For the caregiver, hypotheses 2 and 3 were supported with the following evidence. There was a small negative correlation between caregiver communication and dyadic strain. Caregiver appraisal of patient decision making had a moderate negative correlation with dyadic strain and a small positive correlation with dyadic interactions. Caregiver reciprocity correlated moderately with dyadic interactions and negatively with dyadic strain. For the caregiver, hypothesis 4 was also partially supported in that caregiver CES-D scores inversely correlated with caregiver communication and with reciprocity (see Table 8).

\section{Discussion}

A goal in refining the SCl- $\mathrm{R}$ was to find a meaningful factor structure for both patients and 
caregivers that could be used to assess family care interactions. The data supported a three-factor structure as originally conceptualized for both groups, and internal consistency was acceptable. The conceptualization of shared care as three unique components was supported by low to moderate correlations between patient factors with patient factors, and caregiver factors with caregiver factors. Although the variance explained by the factor structures was moderate (46\% for patients and $47 \%$ for caregivers), this is not considered unusual for psychosocial instruments. For example, Heo, Moser, Riegel, Hall, and Christman (2005) found the Minnesota Living With Heart Failure Questionnaire explained $45 \%$ of the variance in health-related quality of life.

For statistical and conceptual reasons, five similar items were deleted from both patient and caregiver versions of the 24-item SCI-R. These items had low factor loadings and item-to-total correlations in both groups. Low item-to-total correlations suggested that these items may lack ability to discriminate, may be excessively easy or difficult, ambiguous, and may have little to do with the domains of shared care (Nunnally \& Bernstein, 1994).

The final version of the SCI-R consisted of 19 items. In both groups items loaded as conceptualized except for two items in the patient structure. One communication item loaded with reciprocity, and one reciprocity item loaded with decision making. Because reciprocity often requires communication, it is not surprising that the communication item, Having someone to talk to, loaded with reciprocity. The patient reciprocity item, Help the caregiver evaluate a situation, may be related to the patient's own decision-making capacity.

The data supported communication, decision making, and reciprocity as components of shared care. Researchers identified communication and agreement between family members as important components of family care (Horowitz, Goodman, \& Reinhardt, 2004; Lyons et al., 2002). Shared care communication about symptoms, feelings, and advice may help dyads shape meanings for their experiences and develop a shared understanding of their situations. Several researchers identified decision making as an important component of family care (Deimling et al., 2001) and a central component of patient autonomy (Davies, Laker, \& Ellis, 1997).

The nature of the reciprocity factor denoted that partnership, empathy, and listening were important attributes in shared care. Researchers proposed that patients not only receive support from, but also provide substantial assistance to their family member, and these acts of reciprocity are important to well-being (Wolff \& Agree, 2004). Reis and Collins (2000) suggested that long-term relationships provide multiple opportunities to reverse the role of support seeker and support provider. This study corroborates Reis and Collins's proposed association between a relationship's duration and supportive exchanges, in that the average duration of the dyad's 
relationship was 42 years, and $43 \%$ percent of the patients and $28 \%$ of caregivers reported that they were both a giver and recipient of care.

In the current study, moderate correlations between patient and caregiver shared care components and positive dyadic interactions imply that shared care varies with positive interactions. Components of shared care also had inverse relationships with strain and depressive symptoms. Because of the cross-sectional data, the direction of these associations is not known. Future research could clarify the relationship strength and direction between components of shared care, the dyadic relationship, and depressive symptoms. For example, does low patient reciprocity lead to strain, or does strain contribute to low reciprocity?

Because depressive symptoms are an important clinical issue, it is interesting to note that patients perceived less reciprocity and had more depressive symptoms than caregivers. Lebowitz and colleagues (1997) suggested that chronic illness is related to depressive symptoms. High rates of depressive symptoms are also reported for persons with heart disease (Sullivan, Levy, Russo, \& Spertus, 2004; Turvey, Schultz, Arndt, Wallace, \& Herzog, 2005). Jiang and colleagues (2004) observed in chronic heart failure patients that depressive symptoms alone predicted a significantly worse prognosis. Receiving assistance without the opportunity to reciprocate can contribute to emotional distress (Davey \& Eggebeen, 1998; Liang et al., 2001). Future studies are needed to describe how shared care components influence outcomes for both the patient and caregiver (e.g., depressive symptoms, self care).

Several researchers identified that some challenges in family care research are to develop methods and tools to study the dynamic characteristics of close relationships in family care (Martire, Lustig, Schulz, Miller, \& Helgeson, 2004; Reis \& Collins, 2000). Researchers previously conceptualized communication, reciprocity, and decision making separately; however, the family care literature may be advanced by conceptualizing and measuring a construct that effectively captures the interactive effects of these components. Measuring shared care can assist researchers and practitioners with identifying family care difficulties, guide interventions to assist with these difficulties, and improve outcomes for both.

Limitations of this study are its homogeneous and small sample of home health care patients and caregivers. The sample was primarily from a Midwestern state, White, elderly, with chronic physical illnesses, and receiving home health care services. The primary patient diagnoses were circulatory, musculoskeletal, and neoplasm. Including a more culturally diverse sample would help elucidate how shared care is influenced by social, cultural, and economic factors. Measuring shared care in a sample of individuals with mild to moderate cognitive impairment is also warranted. It is possible that patients with mild to moderate cognitive 
impairment are able to answer questions about their own care and preferences with accuracy and reliability.

The purpose of this study was to create a measure of shared care that is statistically sound and meaningful for both members of a family care dyad. The data supported a three-factor structure as originally conceptualized. Reliability and construct validity findings from this study support continued use of the Shared Care Instrument-Version 3 (SCl-R). The measurement of shared care with a psychometrically sound instrument for both patients and caregivers offers researchers and practitioners a way to study supportive interactions inclusive of patients and caregivers. Based on this study, the revised instrument, SCI-R, is being employed with a sample of heart failure patients and their family caregivers to examine the influence of shared care on self care in heart failure.

\section{Acknowledgments}

This study was supported by University of Wisconsin-Madison School of Nursing, postdoctoral fellowship DHHS PHS NIH NINR [T32 NR07102] (Ward). University of Wisconsin-Milwaukee Age and Community Faculty Fellowship Program, and College of Nursing.

\section{References}

Archbold, P. G., Baker, J. C., Buckwalter, K. C., Burgio, L., Clark, P. C., Gitlin, L., et al. (2001). Research in informal caregiving: State of science workgroup meeting summary. Washington, DC: National Institute of Nursing Research.

Archbold, P. G., Stewart, B. J., Greenlick, M. R., \& Harvath, T. A. (1992). The clinical assessment of mutuality and preparedness in family caregivers to frail older people. In S. G. Funk, E. M. Tornquist, M. T. Champagne, \& L. A. Copp (Eds.), Key aspects of elder care (pp. 328-339). New York: Springer Publishing.

Bass, D. M., Clark, P. A., Looman, W. J., McCarthy, C. A., \& Eckert, S. (2003). The Cleveland Alzheimer's managed care demonstration: Outcomes after 12 months of implementation. Gerontologist, 43 (1), 73-85.

Bass, D. M., McKee, J., Deimling, G. T., \& Mukherjec, S. (1994). The influence of a diagnosed mental impairment on family caregiver strain. Journal of Gerontology: Social Sciences, 49 (3), 146-155.

Bass, D. M., Tausig, M. B., \& Noelker, L. S. (1989). Elder impairment, social support, and caregiver strain: A framework for understanding support's effects. Journal of Applied Social Sciences, 13 (1), 80-115. 
Beach , S. R., Schulz, R., Williamson, G. M., Miller, L. S., Weiner, M. F., \& Lance, C. E. (2005). Risk factors for potentially harmful informal caregiver behavior. Journal of the American Geriatrics Society, 53 (2), 255-261.

Beach, S. R., Schulz, R., Yee, J. L., \& Jackson, S. (2000). Negative and positive health effects of caring for a disabled spouse: Longitudinal findings from the caregiver health effects study. Psychology \& Aging, 15 (2), 259-271.

Clark, P. A., Whitlatch, C. J., \& Tucke, S. S. (2005, November). Knowledge and agreement of care preferences and dyadic well-being. Paper presented at the Gerontological Society of America, Orlando, FL.

Cohen, J. (1992). A power primer. Psychological Bulletin, 112, 155-159.

Cohen, S., Gottlieb, B., \& Underwood, L. (2000). Social relationships and health. In S. Cohen, B. Gottlieb, \& L. Underwood (Eds.), Social support measurement and intervention (pp. 3-25). New York: Oxford University Press.

Davey, A., \& Eggebeen, D. J. (1998). Patterns of intergenerational exchange and mental health. Journals of Gerontology Series B-Psychological Sciences \& Social Sciences, 53 (2), 86-95.

Davies , S., Laker, S., \& Ellis, L. (1997). Promoting autonomy and independence for older people within nursing practice: A literature review. Journal of Advanced Nursing, 26 (2), 408-417.

Deimling, G. T., Smerglia, V. L., \& Schaefer, M. L. (2001). The impact of family environment and decision-making satisfaction on caregiver depression: A path analytic model. Journal of Aging \& Health, 13 (1), 47-71.

Donelan, K., Hill, C. A., Hoffman, C., Scoles, K., Feldman, P. H., Levine, C., et al. (2002). Challenged to care: Informal caregivers in a changing health system. Health Affairs, 21(4), 222-231.

Feinberg, L. F., Whitlatch , C. J., \& Tucke, S. S. (2000). Making hard choices: Respecting both voices (Final report to the Robert Wood Johnson Foundation). Cleveland, OH: The Margaret Blenkner Research Institute of Benjamin Rose.

Gayle, B. M., \& Preiss, R. W. (2002). An overview of dyadic processes in interpersonal communication. In M. Allen, R. W. Preiss, B. M. Gayle, \& N. A. Burrell (Eds.), Interpersonal communication research: Advances through meta-analysis (pp. 111-124). Mahwah, NJ: Lawrence Erlbaum Associates.

Grady, K. L., Dracup, K., Kennedy, G., Moser, D. K., Piano, M., Stevenson, L. W., et al. (2000). Team management of patients with heart failure: A statement for healthcare 
professionals from the Cardiovascular Nursing Council of the American Heart Association. Circulation, 102(19), 2443-2456.

Heo, S., Moser, D. K., Riegel, B., Hall, L. A., \& Christman, N. (2005). Testing the psychometric properties of the Minnesota Living With Heart Failure questionnaire. Nursing Research, 54(4), 265-272.

Horowitz, A., Goodman, C., \& Reinhardt, J. (2004). Congruence between disabled elders and their primary caregivers. The Gerontologist, 44 (4), 532-542.

Jiang, W., Kuchibhatla, M., Cuffe, M. S., Christopher, E. J., Alexander, J. D., Clary, G. L., et al. (2004). Prognostic value of anxiety and depression in patients with chronic heart failure. Circulation, 110 (22), 3452-3456.

Kenny, D., Kashy, D., \& Cook, W. (2006). Dyadic data analysis. New York: Guilford Press.

Kramer, B. J. (1997). Gain in the caregiving experience: Where are we? What next? Gerontologist, 37 (2), 218-232.

Lebowitz, B. D., Pearson, J. L., Schneider, L. S., Reynolds, C. F., 3rd, Alexopoulos, G. S., Bruce, M. L., et al. (1997). Diagnosis and treatment of depression in late life. Consensus statement update. Journal of the American Medical Association, 278 (14), 1186-1190.

Liang, J., Krause, N. M., \& Bennett, J. M. (2001). Social exchange and well-being: Is giving better than receiving? Psychology and Aging, 16 (3), 511-523.

Lyons , K. S., Zarit, S. H., Sayer, A. G., \& Whitlatch, C. J. (2002). Caregiving as a dyadic process: Perspectives from caregiver and receiver. Journals of Gerontology Series B-Psychological Sciences and Social Sciences, 57 (3), P195-204.

Martire , L. M., Lustig, A. P., Schulz, R., Miller, G. E., \& Helgeson, V. S. (2004). Is it beneficial to involve a family member? A meta-analysis of psychosocial interventions for chronic illness. Health Psychology, 23 (6), 599-611.

McDowell, I. (2006). Measuring health (3rd ed.). New York: Oxford University Press.

Menne, H. L. (2006). A stress process model of chronic illness: Understanding the well-being and decision-making involvement of individuals with dementia. Unpublished dissertation, Case Western Reserve University, Cleveland, $\mathrm{OH}$.

Mor, V., Laliberte, L., Morris, J. N., \& Wiemann, M. (1984). The Karnofsky Performance Status Scale. An examination of its reliability and validity in a research setting. Cancer, 53(9), 2002-2007.

Nunnally, J. M., \& Bernstein, I. R. (1994). Psychometric theory. New York: McGraw-Hill Series in Psychology.

Pett, M. A., Lackey, N. R., \& Sullivan, J. J. (2003). Making sense of factor analysis. The use of 
factor analysis for instrument development in health care research. Thousand Oaks, CA: Sage Publications.

Poulshock, S. W., \& Deimling, G. T. (1984). Families caring for elders in residence: Issues in the measurement of burden. Journal of Gerontology, 39 (2), 230-239.

Pruchno, R. A., Burant, C. J., \& Peters, N. D. (1997). Typologies of caregiving families: Family congruence and individual well-being. Gerontologist, 37 (2), 157-167.

Radloff, L. S., \& Teri, L. (1986). Use of the Center for Epidemiological Studies Depression Scale with older adults. Clinical Gerontologist, 5, 119-135.

Reis, H. T., \& Collins, N. (2000). Measuring relationship properties and interactions relevant to social support. In S. Cohen, L. G. Underwood, \& B. J. Gottlieb (Eds.), Social support measurement and intervention (pp. 136-192). New York: Oxford University Press.

Riegel , B., Carlson, B., Moser, D. K., Sebern, M., Hicks, F. D., \& Roland, V. (2004). Psychometric testing of the self-care of heart failure index. Journal of Cardiac Failure, 10 (4), 350-360.

Schafer, J. L. (1997). Analysis of incomplete multivariate data. London: Chapman \& Hall.

Sebern, M. (1996). Explication of the construct of shared care and the prevention of pressure sores in home health care. Research in Nursing and Health, 19, 183-192.

Sebern, M. (2005a). Psychometric evaluation of the shared care instrument in a sample of home health care family dyads. Journal of Nursing Measurement, 13 (3), 175-191.

Sebern, M. (2005b). Shared care, elder and family member skills used to manage burden. Journal of Advanced Nursing, 52 (2), 170-179.

Sebern , M., \& Whitlatch, C. J. (2007). Dyadic Relationship Scale: A measure of the impact of the provision and receipt of family fare. Gerontologist, 47, 741-751.

Statistical Package for the Social Sciences. (1999). SPSS base (Version 9.0). Chicago: Author.

Sullivan , M., Levy, W. C., Russo, J. E., \& Spertus, J. A. (2004). Depression and health status in patients with advanced heart failure: A prospective study in tertiary care. Journal of Cardiac Failure, 10 (5), 390-396.

Turvey, C. L., Schultz, K., Arndt, S., Wallace, R. B., \& Herzog, R. (2005). Prevalence and correlates of depressive symptoms in a community sample of people suffering from heart failure. Journal of the American Geriatrics Society, 50 (12), 2003-2008.

Wolff, J. L., \& Agree, E. M. (2004). Depression among recipients of informal care: The effects of reciprocity, respect, and adequacy of support. Journals of Gerontology Series B-Psychological Sciences and Social Sciences, 59 (3), S173-180.

Zarit, S., Reever, K., \& Bach-Peterson, J. (1980). Relatives of the impaired elderly: Correlates of 
feelings of burden. The Gerontologist, 20, 649-655. 


\section{Appendix}

\section{Table 1: Demographic Characteristics of Patient and Caregiver Participants}

\begin{tabular}{|c|c|c|}
\hline Demographic Item & Patients & Caregivers \\
\hline Age & $\begin{array}{c}M=66.6, S D=14.3 \text { years }(n= \\
223)\end{array}$ & $M=64, S D=15$ years $(n=220)$ \\
\hline Gender: Female & $44 \%(97)$ & $64 \%(138)$ \\
\hline \multicolumn{3}{|l|}{ Race } \\
\hline White & $98 \%(216)$ & $96.0 \%(206)$ \\
\hline Black & $1 \%(2)$ & $2.0 \%(5)$ \\
\hline American Indian & & $1.4 \%(3)$ \\
\hline Other & $<1 \%(1)$ & $<1.0 \%(2)$ \\
\hline \multicolumn{3}{|l|}{ Ethnicity } \\
\hline Hispanic & $1 \%(2)$ & $1.4 \%(3)$ \\
\hline \multicolumn{3}{|l|}{ Education } \\
\hline College degree/postcollege & $20 \%(44)$ & $21 \%(46)$ \\
\hline High school diploma & $63 \%(141)$ & $62 \%(135)$ \\
\hline Less than high school & $16 \%(37)$ & $16 \%(36)$ \\
\hline \multicolumn{3}{|l|}{ Role relationship } \\
\hline Spouse or partner & $80.7 \%(180)$ & $79.0 \%(175)$ \\
\hline Son, daughter, friend & $7.6 \%(17)$ & $12.0 \%(26)$ \\
\hline Parent & $6.7 \%(15)$ & $4.5 \%(10)$ \\
\hline Other & $5 \%(11)$ & $4.0 \%(9)$ \\
\hline Years of relationship & $\begin{array}{c}M=41 \text { years, } S D=17 \\
\text { Median } 45\end{array}$ & $\begin{array}{c}M=42 \text { years, } S D=17 \\
\text { Median } 47\end{array}$ \\
\hline Functional performance & Median 4 & Median 5 \\
\hline Medical diagnosis & $(n=184)$ & \\
\hline Circulatory & $27 \%(53)$ & \\
\hline Musculoskeletal & $13 \%(25)$ & \\
\hline Neoplasm & $9 \%(18)$ & \\
\hline Disease of skin & $8 \%(16)$ & \\
\hline Digestive system & $5 \%(10)$ & \\
\hline Endocrine & $5 \%(10)$ & \\
\hline Injury poisoning & $5 \%(10)$ & \\
\hline Genitourinary system & $5 \%(10)$ & \\
\hline Paraplegia & $4 \%(9)$ & \\
\hline Symptoms ill defined & $3 \%(7)$ & \\
\hline Respiratory & $3 \%(6)$ & \\
\hline Parkinson's & $3 \%(5)$ & \\
\hline Blood and infectious disease & $1 \%(3)$ & \\
\hline Congenital anomalies & $1 \%(2)$ & \\
\hline
\end{tabular}


Table 2: SCI-R Patient and Caregiver Scale Statistics and Cronbach's Alphas

\begin{tabular}{lllll}
\hline Factor/Scale & Scale Item Means & $\begin{array}{l}\text { Subscale/Scale } \\
\text { Means }(S D)\end{array}$ & $\begin{array}{l}\text { Item-Total Score } \\
\text { Correlation } \\
\text { [Ranges] }\end{array}$ & Cronbach $\alpha$ \\
\hline $\begin{array}{l}\text { Communication } \\
\text { Five Items }\end{array}$ & $\mathrm{PT}=2.9$ & $\mathrm{PT}=14.5(2.6)$ & $\mathrm{PT}=0.36-0.66$ & $\mathrm{PT}=0.75$ \\
Decision Making & $\mathrm{CG}=2.8$ & $\mathrm{CG}=14.2(2.7)$ & $\mathrm{CG}=0.46-0.62$ & $\mathrm{CG}=0.76$ \\
Six items & $\mathrm{CG}=2.9$ & $\mathrm{PT}=18.1(2.0)$ & $\mathrm{PT}=0.36-0.58$ & $\mathrm{PT}=0.74$ \\
Reciprocity & $\mathrm{PT}=2.9$ & $\mathrm{CG}=17.6(2.3)$ & $\mathrm{CG}=0.29-0.53$ & $\mathrm{CG}=0.72$ \\
Eight items & $\mathrm{CG}=3.0$ & $\mathrm{PT}=23.8(2.7)$ & $\mathrm{PT}=0.34-0.61$ & $\mathrm{PT}=0.76$ \\
\hline
\end{tabular}

Note. $\mathrm{PT}=$ patient $(n=220) ; \mathrm{CG}=$ caregiver $(n=223)$. 
Table 3: Comparison of Patient and Caregiver SCI-R Three-Factor Pattern Matrix

\begin{tabular}{|c|c|c|c|c|c|c|}
\hline & \multicolumn{2}{|c|}{ Reciprocity } & \multicolumn{2}{|c|}{ Communication } & \multicolumn{2}{|c|}{ Decision Making } \\
\hline & CG & PT & CG & PT & CG & PT \\
\hline R26 I check it & .78 & .30 & & & & \\
\hline R20 I would feel bad & .64 & .55 & & & & \\
\hline R19 We partner & .57 & .68 & & & & \\
\hline R33 I can do it & .54 & .48 & & & & \\
\hline R32 We see MD together & .53 & .50 & & & & \\
\hline R18 I listen & .52 & .40 & & & & \\
\hline R30 We figure it out & .46 & .49 & & & & \\
\hline R27 We try something else & .40 & .44 & & & & \\
\hline C2 I don't like to bother by & & & .72 & .69 & & \\
\hline C4 S/he doesn't like to tell & & & .69 & .73 & & \\
\hline $\begin{array}{l}\text { C5 S/he doesn't like to } \\
\text { worry }\end{array}$ & & & .65 & .72 & & \\
\hline C3 I never ask for advice & & .45 & .51 & .50 & & \\
\hline C1 There is no one to talk & & .44 & .47 & .32 & & \\
\hline DM24 S/he decides to call & & & & & .63 & .60 \\
\hline $\begin{array}{l}\text { DM22 S/he does what can } \\
\text { for symptoms }\end{array}$ & & & & & .60 & .64 \\
\hline DM21 S/he gets info & & & & & .57 & .58 \\
\hline DM25 S/he talks to MD & & & & & .56 & .67 \\
\hline DM23 S/he decides to go & & & & & 42 & .42 \\
\hline DM31 S/he does as much & & & & & .42 & .46 \\
\hline
\end{tabular}

Note. PT = patient $(n=220) ; C G=$ caregiver $(n=223)$. Extraction method: principal axis factoring. Rotation method: varimax with Kaiser normalization. Rotation converged in 5-7 iterations. 
Table 4: SCI-R Patient and Caregiver Factor Score Correlation Matrix (19 Items)

\begin{tabular}{lcc}
\hline Factor & Reciprocity & Decision Making \\
\hline Decision Making & $\mathrm{PT}=0.41$ & \\
& $\mathrm{CG}=0.37$ & \\
Communication & $\mathrm{PT}=0.15$ & $\mathrm{PT}=-0.04$ \\
& $\mathrm{CG}=0.40$ & $\mathrm{CG}=0.38$ \\
\hline
\end{tabular}

Note. $\mathrm{PT}=$ patient $(n=220) ; \mathrm{CG}=$ caregiver $(n=223)$. Patient factors are correlated with other patient factors, and caregiver factors are correlated with other caregiver factors. 
Table 5: Subscale Means, Standard Deviations, and $t$ Values for Patient and Caregiver SCI-R Scales

\begin{tabular}{cccccccc}
\hline & Reciprocity & Communication & $\begin{array}{c}\text { Decision } \\
\text { Making }\end{array}$ & Strain & $\begin{array}{c}\text { Positive } \\
\text { Interaction }\end{array}$ & CSE-D & KPS \\
\hline $\begin{array}{c}\text { Patient } \\
\text { mean } \\
\text { score }\end{array}$ & 23.8 & 14.4 & 18.0 & 7.8 & 12.5 & 16.0 & 4.1 \\
$\begin{array}{c}\text { Caregiver } \\
\text { mean } \\
\text { score }\end{array}$ & $(2.7)$ & $(2.6)$ & $(2.0)$ & $(2.2)$ & $(2.4)$ & $(11.6)$ & $(2.0)$ \\
& & & & & & & \\
$t$ values & $(3.0)$ & 14.4 & 17.7 & 7.6 & 12.4 & 11.6 & 4.0 \\
& & $(2.6)$ & $(2.4)$ & $(2.3)$ & $(2.4)$ & $(9.3)$ & $(1.9)$ \\
\end{tabular}

Note. PT $=$ patient $(n=191) ; \mathrm{CG}=$ caregiver $(n=191)$; degrees of freedom for Student's $t$ test $=190$.

${ }^{*} p<.05 ;{ }^{* *} p<.001$. Standard deviations for each mean are in parentheses. 
Table 6: Pearson Correlation Coefficients Between Patient Scores and Caregiver Scores

\begin{tabular}{|c|c|c|c|c|c|c|}
\hline & $\begin{array}{l}\text { PT Positive } \\
\text { Interaction }\end{array}$ & $\begin{array}{l}\text { PT Dyadic } \\
\text { Strain }\end{array}$ & $\begin{array}{c}\text { PT } \\
\text { Reciprocity }\end{array}$ & $\begin{array}{c}\text { PT } \\
\text { Communication }\end{array}$ & $\begin{array}{l}\text { PT Decision } \\
\text { Making }\end{array}$ & PT CES-D \\
\hline $\begin{array}{l}\text { CG Positive } \\
\text { Interactions }\end{array}$ & $0.35^{\star *}$ & & & & & \\
\hline $\begin{array}{l}\text { CG Dyadic } \\
\text { Strain }\end{array}$ & & $0.37^{* *}$ & & & & \\
\hline CG Reciprocity & & & $0.47^{\star *}$ & & & \\
\hline $\begin{array}{l}\text { CG } \\
\text { Communication }\end{array}$ & & & & $0.41^{* *}$ & & \\
\hline $\begin{array}{l}\text { CG Decision } \\
\text { Making }\end{array}$ & & & & & $0.38^{* *}$ & \\
\hline CG CES-D & & & & & & $0.23^{* *}$ \\
\hline
\end{tabular}

Note. Correlations are based on matched pairs for patients and family caregivers $(n=198)$. PT = patient; CG = caregiver.

** Significance test (2-tailed) $p<.001$. 
Table 7: Patient Data: Pearson Correlations Between Shared Care and Positive Dyadic Interactions, Dyadic Strain, and CES-D Scores $(n=223)$

\begin{tabular}{llccc}
\hline Patient & Positive Dyadic & Dyadic Strain & CES-D \\
\hline $\begin{array}{l}\text { Shared Care } \\
\text { Subscales }\end{array}$ & Reciprocity & $0.49^{\star *}$ & $-0.30^{* *}$ & -0.06 \\
& Communication & 0.04 & $-0.35^{\star *}$ & $-0.27^{\star *}$ \\
& Decision Making & $0.29^{* *}$ & $-0.17^{* *}$ & -0.07 \\
\hline
\end{tabular}

${ }^{\star} p<0.05$ level (2-tailed). ${ }^{* *} p<0.001$ level (2-tailed). 
Table 8: Caregiver Data: Pearson Correlations Between Shared Care and Positive Dyadic Interactions, Dyadic Strain, and CES-D Scores $(n=220)$

\begin{tabular}{llccc}
\hline Patient & Positive Dyadic & Dyadic Strain & CES-D \\
\hline $\begin{array}{l}\text { Shared Care } \\
\text { Subscales }\end{array}$ & Reciprocity & $0.35^{\star *}$ & $-0.39^{* *}$ & $-0.20^{\star *}$ \\
& Communication & 0.12 & $-0.26^{* *}$ & $-0.27^{* *}$ \\
& Decision Making & $0.14^{*}$ & $-0.28^{* *}$ & -0.10 \\
\hline
\end{tabular}

${ }^{*} p<0.05$ level (2-tailed). ${ }^{* *} p<0.001$ level (2-tailed). 
Figure 1: Shared care construct

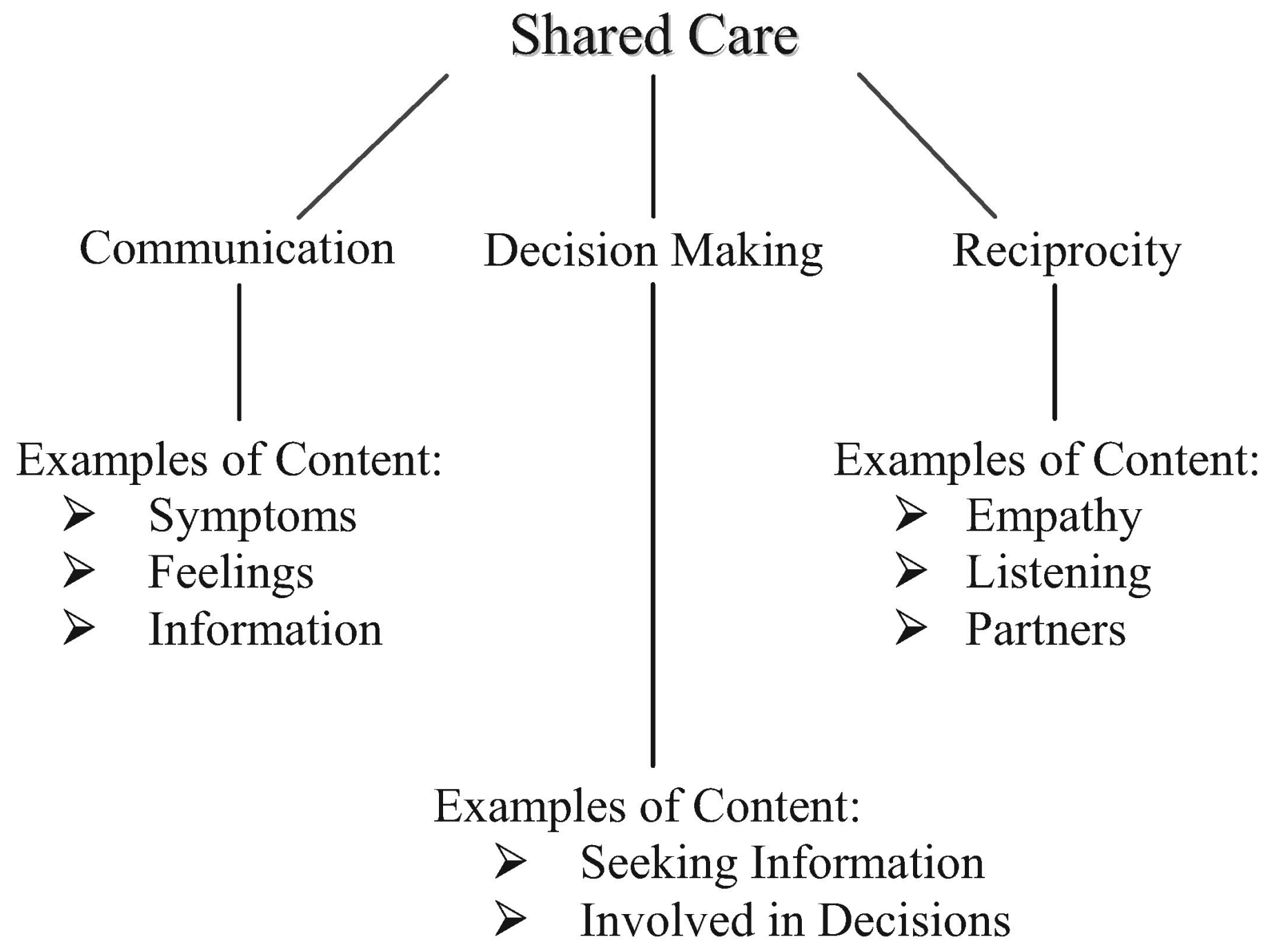

